\title{
EL CONSUMO DE LA POSMODERNIDAD EN LA INDUSTRIA DE LA HOSPITALIDAD
}

\author{
THE CONSUMPTION OF POSTMODERNISM IN THE \\ HOSPITALITY INDUSTRY
}

Pablo R. Manzano-Insuasti ${ }^{1}$

\section{Resumen}

El presente artículo introduce el debate posmoderno en la industria de la hospitalidad, planteándose la interrogante ¿qué aspectos de la posmodernidad influyen en el consumidor de la industria hospitalaria? Se analizan dos casos de estudio, primero en el sector cruceros y segundo en la plataforma virtual Airbnb por medio de la aplicación metodológica de Firat y Shultz (1997) y Brown (1995) respectivamente, concluyendo que el posmodernismo ofrece un medio para conceptualizar los cambios que están teniendo lugar en el ambiente de la hospitalidad contemporánea, evidenciados en la fragmentación de los mercados, el crecimiento de las alianzas estratégicas y el crecimiento de la práctica de comercialización anárquica, enfatizando la unicidad sobre la homogeneidad, investigando la cultura del simulacro y ofreciendo la oportunidad de considerar hasta qué punto la industria hotelera contemporánea representa la sustitución de una ética puritana de consumo, con la cultura consumista asociada con el capitalismo tardío.

\section{Palabras clave}

Posmodernismo, Industria, Hospitalidad, Consumidor, Turismo.

\begin{abstract}
This article introduces the postmodern debate in the hospitality industry, asking the question: what aspects of postmodernism influence the consumer of the hospital industry? Two case studies are analyzed, first in the cruise sector and second in the Airbnb virtual platform through the methodological application of Firat y Shultz (1997) and Brown (1995) respectively, concluding that postmodernism offers a means to conceptualize the changes that are taking place in the environment of contemporary hospitality, evidenced in the fragmentation of markets, the growth of strategic alliances and the growth of anarchic marketing practice, emphasizing the uniqueness of homogeneity, investigating the culture of the simulation and offering The opportunity to consider the extent to which the contemporary hotel industry represents the replacement of a Puritan ethic of consumption with the consumerist culture associated with late capitalism.
\end{abstract}

\section{Key Words}

Postmodernism, Industry, Hospitality, Consumer, Tourism.

\footnotetext{
${ }^{1}$ Universidad Anáhuac (México). Correo electrónico: pablo.manzano@anahuac.mx
} 


\section{Introducción}

¿Hasta qué punto una comprensión de la posmodernidad puede ser útil para examinar la teoría y práctica de la hospitalidad contemporánea? En el presente ensayo se trata de introducir el debate posmoderno y demostrar cómo la teoría y la investigación dentro de la industria de la hospitalidad depende cada vez más del comportamiento del consumidor y su predilección individualizada, sobre un servicio adaptado a sus medidas y exigencias personales. No se pretende discutir en detalle el desarrollo del posmodernismo ni su uso en la investigación de la sociedad contemporánea, centrando su limitación al explorar el posmodernismo frente a las características del consumo de hospitalidad.

Considerando que la comercialización refleja cambios económicos y culturales en la sociedad, es de esperar que las características del posmodernismo se evidencien en la elección y consumo de bienes y servicios. El presente documento permite la explicación de este fenómeno; en primera instancia se analizan ciertas aproximaciones científicas que persigan una definición de la posmodernidad; a continuación se explican sus relaciones con la industria de la hospitalidad, para lo cual, se consideran los esquemas de Firat y Shultz (1997) y Brown (1995) ejemplificando, por medio de dos casos de estudio, el impacto, consecuencias y futuras implicaciones de la transformación posmoderna sobre el criterio del consumidor dentro de la industria de la hospitalidad y, finalmente, se plantean conclusiones entorno al criterio del posmodernismo como medio de conceptualización de los cambios actuales en la industria de la hospitalidad.

Las cuestiones contemporáneas, como la fragmentación de los mercados, el crecimiento de alianzas estratégicas, las alusiones de marketing a la tradición y la autenticidad y el crecimiento de la práctica anarquista del marketing se pueden considerar desde la perspectiva del posmoderno consumidor de productos y servicios de hospitalidad (Foxall, Goldsmith y Brown 1994), ante lo cual, el cambio de enfoque en la captación de nuevos nichos de mercado requiere un análisis metódico de una demanda cada vez más segmentada y exclusiva. Si se aceptan premisas de autores como Thomas (1997), Brown (2000), Firat y Shultz (1997), se evidencia la necesidad de investigar el posmodernismo en relación con el consumo contemporáneo de la hospitalidad.

\section{Breve acercamiento al posmodernismo}

Un tema común que recorre gran parte de la literatura actual sobre el consumo, involucra a la sociedad occidental contemporánea y el uso fragmentado de la naturaleza. Para Ogilvy, (1990) un cambio del consumo ha sido reconocido a partir de valores y creencias basados en la producción industrial en masa y patrones universales de satisfacciones y preferencias personales, como lo demuestran actuales estándares eclécticos de compra y un reconocimiento de las ambigüedades inherentes a los artefactos modernos (Foxall et al., 1994). Con una disminución percibida de los roles sociales fijos, se pretende que los individuos adopten una amplia variedad de identidades en una sociedad posmoderna. Como sugiere Foucault (1980), no existe un yo real, los individuos son libres de construir identidades dentro de una amplia gama disponible y en un proceso de cambio. Ante esto, Ogilvy (1990) refiere que:

Cuando el consumidor moderno compra productos para adornar y expresar un estilo de vida más o menos coherente y reconocible, el consumidor posmoderno juega con una combinación ecléctica de bienes y servicios para experimentar una serie de identidades incoherentes tentativas (p.15).

Este autor continúa argumentando que, mientras que la investigación de mercados tradicional previamente segmentó a la población en grupos de reconocibles consumidores, la investigación de mercados posmoderna tendría que ser emprendida bajo el reconocimiento de que personas no permanecen fieles a un solo concepto de bien o servicio.

\section{Aproximación a la definición del posmodernismo}

No se pretende discutir extensamente el desarrollo y el papel continuo del posmodernismo en la sociedad contemporánea, tales argumentos han sido fundamentados a través de trabajos de autores como Best y Kellner (1991), Baudrillard (1983), Lyotard (1984), Seidman y Wagner (1991) y Foucault (1977), lo que se intenta lograr es la consideración de algunos aspectos clave del posmodernismo y la manera en que se relacionan con características de la sociedad contemporánea, el papel del consumo y, en particular, el consumo de la hospitalidad; para esto es necesario discutir los orígenes del pensamiento posmoderno y discutir brevemente los elementos clave del posmodernismo, el mismo que abarca una amplia gama de estudio, por tal se lo define de maneras diferentes. Brown (1995) menciona que el posmodernismo "es esencialmente intangible; un estado de ánimo, un momento y una perspectiva, el lugar de un cuerpo de teoría o un marco conceptual" (p.10). A su vez, Gellner (1992) propone una visión similar al sugerir que:

...el posmodernismo es un movimiento contemporáneo. 
Es fuerte y está de moda. Por encima de esto, no está del todo claro lo que es...no parece haber ningún manifiesto posmoderno que se pueda consultar para asegurarse que se han identificado adecuadamente sus ideas (p.39).

Del mismo modo, Crotty (1998) refiere al posmodernismo como el "más resbaladizo de los términos"(p.183), definiéndoselo de varias maneras, donde los problemas de enunciación son exacerbados por el hecho de que el posmodernismo ha llegado a significar cosas diferentes dentro de distintas áreas de estudio (Featherstone, 1991), a lo que Brown (1995) añade que "el único punto discernible de consenso entre los posmodernistas es su falta de consenso sobre el posmodernismo"(p.11), lo cual se complementa con el criterio de Jameson (1991) refiriendo que el posmodernismo replica y refuerza la lógica del capitalismo de consumo.

Estos problemas se ven agravados por la incorporación de varias disciplinas en el posmodernismo (Hebdige, 1986); además, la distorsión de los conceptos en los que se basa es inevitable, simplemente siendo un reflejo de su dispersión entre un rango de disciplinas; sin embargo, los problemas con la definición de los conceptos de posmodernidad no son suficientes, razón para rechazar su uso absoluto para una consideración de la comercialización y el consumo en la hospitalidad contemporánea.

\section{Consumir hospitalidad: aprender lecciones del posmodernismo}

Si bien las definiciones competitivas del posmodernismo han hecho que el constructo posmoderno sea controvertido y notoriamente difícil de definir en relación con el consumo de productos y servicios de hospitalidad, se puede argumentar que contiene una serie de principios reconocibles, destacados por Miller y Real (1998) como en el desglose de grandes narrativas, la centralidad de las tecnologías de la comunicación y la cultura de consumo del capitalismo tardío.

\section{El desglose de grandes narrativas}

Se refiere al uso de metanarrativas para resolver problemas generalizados, ante esto Lyotard (1984) lo contempla como central al momento de debatir sobre el posmodernismo relacionado al conocimiento, a través de la introducción de un tema clave: la declinación del poder legitimador de las metanarrativas. De acuerdo a Lyotard, el cambio de narrativas locales y de teorías generales a estrategias pragmáticas sugieren la necesidad de reemplazar el concepto de un universal, racional sujeto de conocimiento por uno individual con múltiples áreas de conocimiento que refleje la ubicación social y la historia (Seidman, 1994), característico de la industria de la hospitalidad.

\section{La centralidad de las tecnologías de la comunicación}

Comprende un punto clave en el posmodernismo por cuanto provee un acceso global hacia una cultura de reproducción masiva, esto es, generar copias sin la presencia de algo original (Baudrillard, 1983); este autor es considerado la primera persona en organizar una teoría social posmoderna (Kellner, 1988), donde refiere al posmodernismo como una representación de un modo alterado de percepción, impulsado en una información instantánea a través de un amplio set de medios de comunicación; como lo sugirió Solomon (1988) "viendo el mundo como una cámara de televisión lo ve, el ojo posmoderno reduce la longitud y la amplitud de la experiencia a un espectáculo bidimensional, un carnaval de imágenes de detención y la superficie seductora”(p.36).

La saturación por la tecnología es una pieza clave de la era posmoderna, en la medida en que se argumenta que los modelos, espectáculos e hiperrealismo de la simulación han reemplazado el valor del uso de las mercancías. Como resultado, se vive en un mundo de simulacros donde la imagen o significante de un evento reemplaza la experiencia actual y el conocimiento de su referente o significado (Miller y Real, 1998), en una sociedad posmoderna, las personas se tornan fascinadas por signos y, como resultado, ellos existen en un estado de hiperrealidad demostrando mayor importancia de lo que ellos representan; de esta forma, los actuales usuarios consumen imaginería y no se enfocan en lo que las imágenes representan o significan. Como Miller y Real (1998) manifiestan "vivimos en un mundo de simulacros donde la imagen o significante de un evento ha reemplazado la experiencia directa y conocimiento de su referente o significado" (p.30).

\section{Lacultura de consumo del capitalismo tardio}

Se refiere a las maneras en que la ética puritana del consumo ha sido reemplazada por una ética comercial de conspicuo consumo (Featherstone, 1991), lo cual es respaldado por Brown (1993) argumentando que "la urgencia de consumir es un síntoma característico, sin embargo, un síntoma característico de la condición posmoderna"(p.50); en una sociedad contemporánea, el consumo se ha convertido en lo más importante gracias a la revolución de la conciencia como resultado de la comunicación masiva, anuncios y publicidad; obteniéndose como consecuencia, la aparición de 
un mundo artificial donde cada deseo por sí solo es manufacturado, lo cual es complementado por Singh (2011) al manifestar que el desarrollo económico, las tendencias demográficas y las nuevas tecnologías son elementos que influyen persuasivamente en el alcance y la escala de la cultura del consumo.

Adicionalmente, en la era posmoderna no se diferencia una distinción natural entre la producción y el consumo; cada acto de consumo es también un acto de producción y viceversa (Firat y Venkatesh, 1995). En la modernidad, el consumo fue visto como un evento secundario y trivializado por ser determinado como una privada y femenina actividad, parte de las actividades de casa (Mort, 1989). En el posmodernismo, el consumo adquiere una gran significancia, tornándose en el significado el cual los individuos definen su existencia y relaciones con otros. Como Bocock (1993) sugiere "La pregunta ¿Quién soy yo? Tiende a ser respondida en términos de patrones de consumo, así como en términos de roles ocupacionales por muchas personas en el capitalismo occidental" (p.109), sin embargo, como lo menciona Bell (1976), el capitalismo estadounidense ha perdido su legitimidad tradicional, basada en un sistema de recompensas enfocado en la satisfacción laboral, sustituido por la facilidad material y el lujo. El reflejo comparativo entre las características modernas frente a las posmodernas se resume a continuación:

Tabla 1. Características modernas / posmodernas

\begin{tabular}{|c|c|}
\hline Énfasis modernista & Énfasis posmodernista \\
\hline Objeto & Imagen/símbolo \\
\hline Sujeto cartesiano & Sujeto simbólico \\
\hline Sujeto cognitivo & Sujeto semiótico \\
\hline Sujeto unificado & Sujeto fragmentado \\
\hline Sujeto centrado & Sujeto descentralizado \\
\hline Significado & Significante \\
\hline Objetificación & Simbolismo \\
\hline Representación & Significación \\
\hline Verdad (objetiva) & Verdad (construida) \\
\hline Real & Hiperreal \\
\hline Universalismo & Localismo \\
\hline Sociedad como estructura & Sociedad como espectáculo \\
\hline Razón logocéntrica & Razón hermenéutica \\
\hline Conocimiento & Comunicación \\
\hline Economía & Cultura \\
\hline Capitalismo & Capitalismo tardío \\
\hline Sistema económico & Sistema simbólico \\
\hline Producción & Consumo \\
\hline Ciencias & Humanidades \\
\hline Centrismo Euro-americano & Globalización \\
\hline Falocentrismo & Feminismo/género \\
\hline Colonialismo & Multiculturalismo \\
\hline
\end{tabular}

Fuente: elaboración propia a partir de Williams (2012).

\section{Aplicando el posmodernismo en el consumo de productos de hospitalidad}

Al momento se ha analizado al postmodernismo por medio de una visión general de las ideas de los principales teóricos del tema. Si bien es necesario como una ayuda a la comprensión, es evidente que tal enfoque también puede ser un punto complicado e inaccesible de entrada en el pensamiento posmoderno. Dentro de un contexto general, el consumidor posmoderno no busca impresionar a otros por medio de su identidad, sino pretende vivir intensamente las identidades que él creó (Hamouda, 2015) generándose un nuevo horizonte para la sociedad posmoderna (Dujmovic, 2015); de esta manera, para aplicar al posmodernismo dentro del consumo de productos y servicios de hospitalidad, se necesita identificar esquemas que simplifiquen algunos de sus aspectos más abstractos. Para este efecto, se presentan dos esquemas de investigación, el primero desarrollado por Firat y Shultz (1997) (ver tabla 2) y el segundo por Brown (1995) (ver tabla 3). Estos esquemas proporcionan una visión de la complejidad del discurso de la posmodernidad, particularmente en lo que se refiere a la comercialización y al comportamiento de los consumidores en la industria de la hospitalidad.

Tabla 2. Condiciones posmodernas: Esquema de Firat \& Shultz

\begin{tabular}{|c|c|}
\hline Condiciones Posmodernas & Breve Definición \\
\hline Franqueza/tolerancia & $\begin{array}{l}\text { Aceptación de las diferencias sin prejuicios } \\
\text { de superioridad e inferioridad. }\end{array}$ \\
\hline Hiperrealidad & $\begin{array}{l}\text { Conformación de la realidad social por } \\
\text { medio de la simulación fuertemente } \\
\text { significada y representada. }\end{array}$ \\
\hline Presente perpetuo & $\begin{array}{l}\text { Propensión cultural a experimentar todo el } \\
\text { presente "aquí y ahora". }\end{array}$ \\
\hline Yuxtaposiciones paradójicas & $\begin{array}{l}\text { Propensión cultural a yuxtaponer cosas } \\
\text { entre sí, incluyendo elementos de oposición, } \\
\text { contradictorios y no relacionados. }\end{array}$ \\
\hline Fragmentación & $\begin{array}{l}\text { Omnipresencia de experiencias inconexas } \\
\text { y desconectadas de la vida y el sentido del } \\
\text { yo, así como la aceptación creciente del } \\
\text { dinamismo. }\end{array}$ \\
\hline Pérdida de compromiso & $\begin{array}{l}\text { Creciente falta de voluntad cultural para } \\
\text { comprometerse con alguna idea, proyecto } \\
\text { o diseño. }\end{array}$ \\
\hline $\begin{array}{l}\text { Descentrando el sujeto } \\
\text { Descentrando el sujeto }\end{array}$ & $\begin{array}{l}\text { Desestimación de la importancia del ser } \\
\text { humano en la cultura moderna. }\end{array}$ \\
\hline Revirtiendo el consumo & $\begin{array}{l}\text { Reconocimiento cultural que el valor es } \\
\text { creado no en la producción sino en el } \\
\text { consumo. }\end{array}$ \\
\hline Enfatizando forma/estilo & $\begin{array}{l}\text { Influencia creciente de la forma y estilo en la } \\
\text { determinación del significado y la vida. }\end{array}$ \\
\hline $\begin{array}{c}\text { Aceptando el desorden/ } \\
\text { caos }\end{array}$ & $\begin{array}{l}\text { Reconocimiento cultural que, en lugar } \\
\text { del orden, las crisis y los desequilibrios } \\
\text { son estados comunes de existencia, y su } \\
\text { posterior aceptación y apreciación de esta } \\
\text { condición. }\end{array}$ \\
\hline
\end{tabular}

Fuente: elaboración propia a partir de Firat y Shultz (1997). 
Tabla 3. Condiciones posmodernas: Esquema de Brown

\begin{tabular}{|c|c|}
\hline Condiciones Posmodernas & Breve Definición \\
\hline Fragmentación & $\begin{array}{l}\text { Refiere la desintegración de una organización } \\
\text { social, economía de mercado de masas y el } \\
\text { "yo" unificado, ante lo cual, se adhieren } \\
\text { imágenes desconectadas generadas por un } \\
\text { medio fragmentado. }\end{array}$ \\
\hline Des-diferenciación & $\begin{array}{l}\text { Comprende la deconstrucción de jerarquías } \\
\text { establecidas (e.g. cultura) y el desenfoque de } \\
\text { previos y aparentes constructos establecidos } \\
\text { (e.g. filosofía/religión o ciencia/religión). }\end{array}$ \\
\hline Hiperrealidad & $\begin{array}{l}\text { Refiere a la pérdida de un sentido de } \\
\text { autenticidad y la tangibilización de lo que } \\
\text { previamente fue simulación, ejemplos } \\
\text { incluyen a parques, hoteles y restaurantes } \\
\text { temáticos. }\end{array}$ \\
\hline Cronología & $\begin{array}{l}\text { Comprende la preocupación por el pasado o } \\
\text { sus representaciones en base a perspectivas } \\
\text { retrospectivas. }\end{array}$ \\
\hline Pastiche & $\begin{array}{l}\text { Consiste en el collage de estilos disponibles, } \\
\text { vistos en la arquitectura, arte, música y } \\
\text { literatura. }\end{array}$ \\
\hline Anti-fundacionalismo & $\begin{array}{l}\text { Se refiere al sentido dentro del } \\
\text { postmodernismo del desconstrucionismo. } \\
\text { Esto se evidencia por una antipatía } \\
\text { hacia la ortodoxia, el establecimiento y } \\
\text { generalizaciones sistemáticas en áreas como } \\
\text { la cienciay el socialismo. Este factor se refiere } \\
\text { al descrédito, dentro del postmodernismo, } \\
\text { de una búsqueda de la verdad universal y } \\
\text { del conocimiento objetivo. }\end{array}$ \\
\hline Pluralismo & $\begin{array}{l}\text { Brown sugiere no estimarlo como una } \\
\text { categoría por sí sola, sino el reflejo del } \\
\text { sentido en que los posmodernistas que } \\
\text { cualquier cosa es aceptable, sin reglas ni } \\
\text { exclusiones. }\end{array}$ \\
\hline
\end{tabular}

Fuente: elaboración propia a partir de Firat y Shultz (1997).

\section{Resultados}

\section{Hospitalidad posmoderna: algunos ejemplos}

Con el fin de explorar detalladamente algunos de los aspectos identificados, a continuación, se incorporan dos estudios de caso, investigando respectivamente las implicaciones posmodernas derivadas en el mercado de cruceros utilizando el esquema proporcionado por Firat y Shultz (1997), y de igual forma en mercado de renta de sitios de alojamiento por medio de la plataforma Airbnb, usando el esquema de marketing de Brown (1995). Ambos estudios de caso buscan identificar las cuestiones clave que enfrentan los operadores actuales dentro de un mercado posmoderno.

\section{Estudio de caso 1}

Para entender las implicaciones del posmodernismo en los consumidores de servicios de hospitalidad se presenta el siguiente ejemplo del mercado de la línea de cruceros. La naturaleza de este mercado en rápido desarrollo y altamente competitivo se encuentra sólidamente documentada (Dale y Robinson, 2001, Formica y Olsen,
1998, McAuley, 1998). Además, la literatura ha citado cambios en el comportamiento de los consumidores y la difuminación de las distinciones tradicionales entre los proveedores de estos servicios y otros operadores de las empresas de hospitalidad

\section{Antecedentes del mercado de cruceros contemporáneo}

1.- Franqueza / tolerancia: brinda una aceptación de diferentes estilos, modos de ser, de vivir y su impacto en la provisión de alojamiento, una aceptación de la preeminencia del cliente como el foco de todas las actividades operacionales, que incorpora la eliminación de las barreras de entrada para todas las "clases" de pasajeros. Este mercado se ejemplifica por la ruptura del orden social tradicional (clases sociales), que van desde la primera clase (los que serían invitados a eventos de lazo blanco) hasta la estiba.

2.- Hiperrealidad: la sustitución de las funciones tradicionales de la provisión de información mediante la manipulación de los deseos, gustos y motivaciones del cliente, el desarrollo rutinario de los mundos de fantasía, que explotan por el embellecimiento y la exageración histórica, dan resonancia a los cruceros. Voyager of the Seas es un ejemplo clásico de simulacridad e hiperrealidad, la pérdida de autenticidad y el devenir real de lo que antes era una simulación, así como el uso de artefactos de una época pasada, pasaron a formar parte de su decoración. Elementos temáticos, como fotografías, brújulas de los buques y equipo de navegación están sujetos a la pared. Voyager of the Seas tiene un teatro llamado La Scala, así como una colección de arte valorada en 7,5 millones de libras, y un centro comercial, el Royal Promenade, inspirado en Burlington Arcade lo que crea una realidad que el turista quiere ver y sentir (Lück, 2007).

3.- Presente perpetuo: la propensión a experimentar el pasado y el futuro en el presente, alusiones a la historia, autenticidad y tradición, todo ello en un ambiente superior a un original romántico. Los empleados de Voyager of the Seas visten uniformes que evocan recuerdos, reales o imaginarios, de los años veinte. Las naves rememoran el pasado con imágenes $y$, al usarlas, niegan su historia, haciéndolas un presente perpetuo. Voyager of the Seas tiene un restaurante principal, incorporado con una decoración de barcos de una época pasada de teca y latón; un restaurante italiano, Portofino, decorado para evocar imágenes de una época más glamorosa anterior, y un comedor de carretera de los años 50 , completo con autos deportivos de aquella época y camareras realizando rutinas coreografiadas de las décadas de los 80 y 90, por ejemplo, YMCA. 
4.- Yuxtaposición paradójica: la propensión a yuxtaponer elementos opuestos, contradictorios y esencialmente no relacionados, por ejemplo, yuxtaponiendo clubes de salud completamente equipados y la disponibilidad de clases de ejercicios con la provisión de numerosos bufetes en todo el barco. Del mismo modo, los operadores de buques de crucero yuxtaponen el minigolf, que debería estar asociados con amplios espacios verdes, con la popa de los barcos y su entorno náutico.

5.- Fragmentación: demostrada por la división de los mercados en segmentos cada vez más pequeños, cada uno con su propia gama de productos cuidadosamente posicionados. La multiplicación de los canales de distribución y las fuentes de los medios de comunicación, lo que conduce indiscutiblemente (aunque no verdaderamente) a una capacidad de entregar mensajes altamente enfocados a grupos específicos de personas. También se incluyen características de hiper-targeting, personalización masiva y micro-marketing. Voyager of the Seas divide a sus jóvenes clientes, entre los tres y los diecisiete años, en cuatro segmentos, cada uno con sus propias actividades y áreas de juego. Además, Royal Caribbean tiene una gama de material promocional para el Voyager of the Seas, dirigida a diferentes mercados.

6.- Pérdida de compromiso: un reconocimiento de que los clientes no están dispuestos a comprometerse con ideas únicas, proyectos o grandes diseños, vinculados con el reconocimiento de que ellos deben ser capaces de identificar una razón para ser leales. Royal Caribbean es sólo una de seis o siete empresas de este tipo que operan más de diez buques cada uno. En total, las seis compañías más grandes operan alrededor de 112 buques. Los cruceros representan un nuevo modo de percepción fomentado por una era de comunicación instantánea (Solomon, 1998), es decir, televisión, internet y redes sociales.

7.- Descentrando el sujeto: el desdibujamiento de fronteras, por ejemplo, clase/estado, cultura alta/ baja, publicidad/información, se evidencia aún más por las distinciones entre ocio y consumo, donde el merchandising mezclado significa que en el Voyager of the Seas, casinos, tiendas de regalos y tiendas de moda ocupan el mismo espacio. Estos buques son altamente regulados, poseen espacios comerciales privados que están expresamente diseñados para hacer dinero. Sin embargo, este propósito es algo disfrazado para evitar ofender a los clientes. Existen cabinas premium que miran hacia el interior del restaurant Royal Promenade, eliminando cualquier pretensión de que la experiencia se enfoca en "ver el mundo".
8.- Revirtiendo el consumo: el rápido crecimiento del mercado de vacaciones de cruceros vinculado a la identificación de mercados y culturas, impulsados por el consumo, lleva a reconocer la importancia del consumo para la sociedad occidental contemporánea. El Voyager of the Seas, lanzado a finales del 2000, ya ha sido acompañado por dos barcos de igual tamaño, el Cunard y el P \& O. Cunard, por ejemplo, está actualmente esperando la entrega del Queen Mary 2 (que será el mayor buque jamás construido, con más de 150000 toneladas, el doble del tamaño del QE2 (Lück, 2007).

9.- Enfatizando la forma / estilo: en este mercado se hace hincapié en los barcos más grandes, el número de oportunidades para la alimentación, el tamaño de los restaurantes, tiendas y bares. Voyager of the Seas tiene el único muro de escalada en el mar, a unos 150 metros sobre el agua; además, posee una pista de hielo a bordo, lo suficientemente grande para albergar espectáculos de hielo de gran consideración. A su vez, los productos complementarios forman parte de la esencia Voyager, de hecho, Royal Caribbean ha arrendado un terreno de 120 hectáreas anexado a Haití para convertirlo en un día de lujo en la playa, destinado a clientes con necesidades de excursiones en tierra.

10.- Aceptando el desorden / caos: comprende la importancia de desarrollar estructuras organizativas capaces de hacer frente de manera efectiva a estados de crisis y desequilibrios. Por ejemplo, Royal Caribbean tiene que abordar casi 4000 pasajeros cuando el Voyager of the Seas sale de Miami. Lo hace en parte mediante la colocación de escritorios dentro de la mayoría de los hoteles locales utilizados por los huéspedes la noche antes de la salida. También es importante desarrollar una fuerza de trabajo y una organización adaptable y flexible por lo que las multidestrezas son comunes en los barcos de crucero como el Voyager.

\section{Estudio de caso No. 2}

El presente caso demuestra un número limitado de ejemplos del consumo posmoderno encontrado en establecimientos Airbnb, donde varias de las características que distinguen al posmodernismo son aplicables al entorno de los nacientes establecimientos Airbnb; este estudio de caso considera el mercado de venta al por menor bajo el esquema propuesto por Brown (1995).

Es evidente que, en base a factores como la intervención del gobierno, los cambios en la sociedad, los avances tecnológicos, el crecimiento de la marca y el avance 
gestionado de la industria han sustituido el desarrollo tradicional y orgánico de los sitios de alojamiento. Algunas de las repercusiones de este cambio se pueden evidenciar al momento de investigar la industria posmoderna del alojamiento.

\section{Antecedentes del sistema de alojamiento bajo la plataforma Airbnb}

La idea de contratar un servicio de alojamiento alternativo a los tradicionales, presentes en el mercado, ha evolucionado en el último decenio. De acuerdo al Portrait of American Travelers cuatro de cada diez personas utilizan alguna plataforma para pernoctar en una residencia privada. En 12 meses, el 30\% de personas que viajaron 3 veces utilizaron una residencia privada, de los cuales el $42 \%$ eran Millenials, 36\% Babyboomers y el $40 \%$ Matures, demostrando el continuo cambio en la predilección de tendencias a la hora de viajar por parte de los turistas (Canaley, 2015).

Estas tendencias se enmarcan dentro del concepto de economía compartida (Geron, 2013), donde, el número de servicios online ha facilitado su crecimiento. A través de ellos, se puede reservar un tipo de acomodación en un destino deseado y con un precio aceptable para el viajero, ya sea en un lugar modesto o de lujo. Un claro ejemplo de este servicio es Airbnb.com, una página web que ofrece acomodación exclusiva en una casa, apartamento, habitación o algo menos convencional como una casa de árbol o un iglú. Fundada en el 2008 por Brian Chesney y Joe Gebbia en San Francisco (USA) (originalmente fue lanzado como Airbedandbreakfast.com) este sitio web permite que una acomodación pueda ser encontrada en casi todo el mundo y su ventaja resalta en su rapidez, claridad, simplicidad y seguridad, siendo descrita en el concepto de Plataformas Vacacionales de Renta Online (PVRO) (Zervas, Proserpio y Byers, 2015).

Airbnb ha creado un novedoso mercado global de compradores para un mercado de vendedores con el fin de rentar espacios desde una plataforma de internet; su crecimiento ha permitido desarrollar la industria del alojamiento inusual con multimillonarias ganancias. Actualmente Aribnb ha servido a 25 millones de huéspedes alrededor del mundo ( 2 millones de habitaciones en el año 2016), con más de un millón de anfitriones localizados en 190 países, y una valoración de la empresa en 20 billones de dólares (Lehr, 2015), lo cual ha generado un cambio considerable en la generación de microempresas de alojamiento, oportunidad de conocer nuevos destinos y mejorar economías locales. Se emplea el esquema de Brown (1995) para identificar el significado posmoderno de sitios de alojamiento bajo la plataforma
Airbnb:

1.- Fragmentación: evidenciado en el crecimiento de la segmentación y la gama de lugares que se ofrecen a los consumidores. Como resultado de los cambios en su mercado, los anfitriones de Airbnb poseen lugares adaptados a las necesidades individuales de los visitantes, donde permanecer en ellos comprende una experiencia diferente a la de un hotel, segmentadas en función de la edad de los clientes, clase social y hábitos de consumo dominante. Estas categorías son utilizadas por los anfitriones para operacionalizar sus establecimientos e identificar sus necesidades particulares. La fragmentación también puede verse en la proliferación de diferentes acomodaciones con la garantía de Airbnb, las cuales incluyen camas de aire, habitaciones extra, apartamentos completos, condominios, casas, botes y prácticamente cualquier lugar que una persona pueda permanecer por un día, semana o mayor tiempo. Este cambio se refleja en la multiplicación de los canales de distribución de la plataforma Airbnb cambiando el concepto del hospedaje moderno en base al número de opciones de localización (Kaplan y Nadler, 2015).

2.- Des-diferenciación: se evidencia dentrodela plataforma Airbnb en base al modelo de negocio peer-to-peer (P2P) (The Economist, 2013) de interacción directa, donde los individuos pueden suplir entre ellos sus necesidades de transacción (proveedores y consumidores) sin necesidad de un intermediario (Prosser, 2013). Esta facilidad de acceso y disminución de costos genera un negocio lucrativo por derecho propio, mismo que es repotenciado para fortalecer la experiencia del usuario a través del anfitrión, comentarios de turistas, actualizaciones de la plataforma, confiabilidad, políticas de seguro para la propiedad e interfaces de redes sociales. De igual forma, la des-diferenciación se enfatiza en el hecho que Aribnb no suple las condiciones de un hotel, pues, genera nuevas experiencias en el turista, al compartir con habitantes locales, descubrir destinos sin tradición turística y recibir una atención diferenciada frente al "automatizado" servicio que oferte una cadena hotelera.

3.- Cronología: se denota en el deseo de autenticidad y en el crecimiento de la demanda de productos tradicionales, lo cual Airbnb cubre perfectamente al poseer una gama muy extensa de anfitriones quienes, al ver incremento en sus visitas, adecúan sus interiores acorde a la realidad histórica que hayan vivido, esto incluye lámparas de gas falsas, bibliotecas falsas, asientos de cuero o fotografías familiares. De igual forma, a través de la sección de experiencias, Airbnb permite al turista vivir nuevas alternativas de visita, desde degustar un desayuno en Tsukiji, un tradicional mercado japonés, hasta admirar al 
Hospital de San Pau en Barcelona, junto a una anfitriona local acompañado de pasteles y té locales. Como resultado de tales vínculos, los anfitriones hacen extensa referencia a su pasado para sugerir estabilidad, permitiendo comercializar una gama de servicios complementarios, utilizando la fuerza de la marca Airbnb para apoyar el lanzamiento de sus servicios.

4.- Pastiche: está disponible de varias maneras relacionadas a los servicios complementarios que se pueden encontrar por medio de Airbnb, dependiendo de la localidad, por ejemplo, el compartir un departamento en el centro de París, y al mismo tiempo jugar en los mejores campos de golf como Fointainebleau o Saint-Cloud. Asimismo, el turista puede aprender a tomar fotografías profesionales en Ciudad del Cabo, o formar parte de las experiencias a compartir, junto con un anfitrión, sobre las historias y degustación de vinos en las calles estrechas de El Born, Barcelona, conociendo casas de tradición catalana, galerías de arte y tiendas de artesanías únicas de estilo.

5.- Anti-fundacionalismo: se considera que el antifundacionalismo incluye aspectos tales como el crecimiento de productos innovadores y ligeramente "arriesgados". El anti-fundacionalismo se basa en promociones percibidas como anarquistas o subversivas, donde la legalidad en la oferta del servicio de alojamiento de Airbnb es de considerable atención. La idea de subversión, en un principio, que genera la plataforma, tiende a no alinearse ante los impuestos y pagos de ley por un servicio de alojamiento, a pesar de ello, la empresa sugiere a los usuarios el revisar las reglas particulares de la localidad, restricciones zonales y regulaciones de impuestos en el país y ciudad anfitriona.

6.- Pluralismo e hiperrealidad: estos argumentos son los mejores ilustradores del posmodernismo en el sector del alojamiento contemporáneo. La hiperrealidad se ha convertido en una rutina en el alojamiento alternativo que presenta Airbnb, desarrollando conceptos minimalistas y decorativos que satisfagan exigencias de una demanda cada vez más individualizada. Apartamentos que simulan cabañas en el Caribe, casas con naturaleza artificial en el centro urbano de Quito, son algunos ejemplos de una simulación adaptada para el turista y su satisfacción. La hiperrealidad se encuentra de igual forma en las experiencias que el turista desea vivir, como el conocer a estrellas de cine en el Museo "Madame Tussauds" de New York, o el formar parte de una danza shamánica ritual en la amazonía ecuatoriana. Con el fin de ganar dinero, sin embargo, esta reversión a la tradición está respaldada por tecnología de vanguardia, incluyendo sofisticados sistemas de control financiero, sistemas de entretenimiento tecnológicamente avanzados y una adaptación hiperreal en un mercado posmoderno. A su vez, cada oferta generada a través de la plataforma Airbnb posee la singularidad que, en alguna parte del mundo, será aceptada, pero a nivel general, posee el carácter de pluralista, aceptado en una sociedad posmoderna, sin recurrir a reglas ni condiciones para que cualquier persona tome la decisión de optar por un alojamiento o vivir una experiencia expuesta en la plataforma.

\section{Conclusiones}

Como se ha podido analizar, el posmodernismo ofrece un medio de conceptualizar los cambios que están teniendo lugar en el ambiente de la hospitalidad contemporánea, evidenciados en aspectos como: la fragmentación de los mercados, el crecimiento de las alianzas estratégicas, las alusiones de marketing a la tradición y la autenticidad y crecimiento de la práctica de comercialización anárquica, los cuales pueden verse fácilmente desde una perspectiva postmoderna, donde el marketing está a la vanguardia de este entorno, ejemplificados en los casos analizados del Voyager of the Seas y Airbnb.

¿Cuáles son las implicaciones de esto para los individuos y las compañías implicadas en la industria de la hospitalidad? Elliot (1993) sugiere que en una sociedad posmoderna los significados están determinados no por los vendedores, sino por los consumidores, resultando que las interpretaciones inconsistentes se conviertan en norma. Esto tiene serias implicaciones para las empresas que buscan identificar los mercados con el fin de determinar las políticas de inversión, recursos humanos y operacionales, lo que es sugerido por Featherstone (1991) al manifestar que se ha pasado de un sistema jerárquico de grupos de status social fijo a uno en el cual los individuos son libres de optar por una amplia gama de estilos de vida, afirmando que "hoy no hay moda: sólo modas, no hay reglas, sólo elecciones, todo el mundo puede ser cualquiera".

Además, es probable que se justifique concluir que el posmodernismo ofrece una serie de oportunidades para investigar el consumo de productos y servicios de hospitalidad. El análisis de Voyager of the Seas basado en el esquema de Firat y Schultz presenta un consumidor exclusivo y una oferta adaptada a cada necesidad, con un continuo proceso de adaptabilidad ante las exigencias del cliente, y, Brown (1995) al ofrecer un esquema que considera posibles enfoques adaptados a la investigación de la hospitalidad en el caso de Airbnb; sugiere que la investigación sobre el postmodernismo en el marketing puede seguir cualquiera de las categorías destacadas en su modelo para analizar individualmente las necesidades del consumidor posmoderno y tomar estrategias de negocio. 
Se han realizado varios estudios para investigar el comportamiento de los consumidores en las decisiones de compra (Tauber, 1972 y Buttle, 1986); sin embargo, gran parte de la investigación en esta área, incluyendo los dos estudios efectuados en el presente ensayo, tienden a centrarse en el consumo de servicios y a considerar el consumo como un estado internalizado. La investigación futura tiene que centrarse específicamente en la industria de la hospitalidad y debe basarse en una suposición construccionista en lugar de positivista, considerando los motivos no como estados internalizados, sino en términos descriptivos o ascriptivos de los actos contextualizados.

Si las empresas deben ser eficaces en el entorno altamente competitivo que comprende la industria de la hospitalidad contemporánea, es imprescindible que entiendan a los consumidores contemporáneos y su toma de decisiones; se puede sugerir que muchos de los enfoques que se están llevando a cabo actualmente se basan en los modelos discutiblemente defectuosos del concepto de marketing. La industria tiene que reconocer que en la sociedad occidental contemporánea los consumidores posmodernos de hospitalidad no adoptan estilos de vida reconocibles consistentes, sino que optan por experimentar una combinación ecléctica de bienes y servicios para experimentar una gama de identidades, a menudo conflictivas.

A su vez, lo que el postmodernismo ofrece a los investigadores de la hospitalidad se basa en tres aspectos, primero, el posmodernismo enfatiza la unicidad sobre la homogeneidad, ofreciendo ideas más significativas sobre el comportamiento del consumidor individual y la oportunidad de liberación investigativa, desglosando las grandes narrativas utilizadas como marcos para comprender la industria de la hospitalidad. En segundo lugar, el posmodernismo brinda la oportunidad de investigar la cultura del simulacro, que es la esencia misma de la industria de la hospitalidad y, por último, el posmodernismo ofrece la oportunidad de considerar hasta qué punto la industria hotelera contemporánea representa la sustitución de una ética puritana de consumo con la cultura consumista asociada con el capitalismo tardío.

\section{Referencias}

1. Baudrillard, J. (1983). Simulations. New York: Semiotext(e).

2. Bell, D. (2011). The cultural contradictions of capitalism. The Hedgehog Review, 13(3), 65-72.

3. Best, S. \& Kellner, D. (1991). Postmodern Theory. Critical Interrogations. Guilford Press.

4. Bocock, R. (1993).Consumption. London: Routledge.

5. Brown, S. (1993). Postmodern marketing. European Journal of Marketing, 27(4),19-34.

6. Brown, S. (1995). Postmodern Marketing. London, Routledge.

7. Buttle, F. A. (1986). Unserviceable concepts in service marketing. Quarterly Review of Marketing, 11(3), 94-102.

8. Canaley, B. K. (2015). El cambio del comportamiento del consumidor hacia la economía compartida: un estudio de Airbnb y como está afectando el viajero moderno. Madrid: Universidad Pontificia Comillas.

9. Crotty, M. (1998). The foundations of social research: Meaning and perspective in the research process. Sage.

10. Cruise Market Watch (2015). Recuperado 19 de febrero 2020, de http://www.cruisemarketwatch. com/market-share/

11. Dale, A. y Robinson, B. (2001). The theming of tourism education, International Journal of Contemporary Hospitality Management, 13(1), 3035.

12. Dickinson, B. y Vladimir, A. (1997). Selling the Sea: An Inside Look at the Cruise. Wiley.

13. Dujmovic, M. (2015). Postmodern society and tourism. In 3rd International Scientific Conference Tourism in Southern and Eastern Europe.

14. Elliot, R. (1993). Marketing and the meaning of postmodern consumer culture. Ponencia presentada en el simposio Rethinking Marketing: New Perspectives on the Discipline and Profession. Coventry, Warwick Business School, University of Warwick. 
15. Featherstone, M. (1991). Consumer Culture \& PostModernism. London: Sage.

16. Firat, A. F. (1991). Postmodern culture, marketing and the consumer. In Marketing Theory and Application (T. Childers, ed.), AMA.

17. Firat, A. F. \& Shultz, C. J. (1997). From segmentation to fragmentation. European Journal of Marketing, $31(3 / 4), 183-207$.

18. Firat, A. F. \& Venkatesh, A (1995). Liberatory postmodernism and the re-enchantment of consumption. Journal of Consumer Research, 22 (3), 239-267.

19. Formica, S. \& Olsen, M. D. (1998). Trends in the amusement park industry. International Journal of Contemporary Hospitality Management, 10 (7), 297.

20. Foucault, M. (1977). Discipline and Punish: The Birth of the Prison. Tr. A. Sheridan. London: Allen Lane Penguin.

21. Foucault, M. (1980). Power, Knowledge and Other Writings 1972-1977. Harvester.

22. Foxall, G. R., Goldsmith, R. E., \& Brown, S. (1994). Consumer psychology for marketing. Thompson.

23. Gellner, E. (1992). Postmodernism, Reason \& Religion. London and New York. Routledge.

24. Geron, T. (2013). Airbnb and the Unstoppable Rise of the Share Economy. Forbes. Recuperado el 10 de noviembre del 2019 de http://www.forbes.com/ sites/tomiogeron/2013/01/23/ airbnb-and-theunstoppable-rise-of-the-share-economy/

25. Hamouda, M. (2015). The postmodern consumer: an identity constructor? In Marketing Dynamism \& Sustainability: Things Change, Things Stay the Same. (pp. 612-620). Springer, Cham.

26. Hebdige, D. (1986). Postmodernism and the other side. Journal of Communication Inquiry, 10 (2), 78-98.

27. Jameson, F. (1991). Postmodernism and Consumer Society, Anti-Aesthetic içinde, ed. Hal Foster, Port
Townsend, Washington.

28. Kaplan, R. A., \& Nadler, M. L. (2015). Airbnb: A case study in occupancy regulation and taxation. $U$. Chi. L. Rev. Dialogue, 82, 103.

29. Kellner, D. (1988). Postmodernism as a social theory: some challenges and problems. Theory, Culture and Society, 5, 239-269.

30. Lehr, D. D. (2015). An analysis of the changing competitive landscape in the hotel industry regarding Airbnb. Graduate Master's Theses, Capstones, and Culminating Projects. 188.

31. Lück, M. (2007). Nautical tourism development: opportunities and threats. Nautical tourism: concepts and issues. Cognizant Communication Corporation, New York.

32. Lyotard, J. F. (1984). The Postmodern Condition - a Report on Knowledge. Manchester University Press.

33. McAuley, A. (1998). Editorial. Journal of Marketing Practice, 4(3), 1.

34. Miller, G. \& Real, M. (1998). Postmodernity and popular culture. In The Postmodern Presence (A. A. Berger, ed.), Sage.

35. Ogilvy, J. (1990). This postmodern business. Marketing and Research Today, 18(1), 4-20.

36. Prosser, D. (2013), Peer-to-Peer Lending: Here Come the Brits, FORBES, Recuperado el 10 de noviembre de 2019 de http://www.forbes.com/ sites/davidprosser/2013/10/24/peer-to-peerlendinghere-come-the-brits/

37. Scull, T. (2001). Cruise operators steer clear of recession. The Times, 14 July, p. 46.

38. Seidman, S. (1994). The Postmodern Turn - New Perspectives on Social Theory. Cambridge University Press.

39. Seidman, S., \& Wagner, D. (1991). Social theory as narrative with a moral intent: a postmodern intervention. Postmodernism and Social Theory 
(Oxford: Basil Blackwell), 47-81.

40. Singh, P. R. (2011). Consumer culture and postmodernism. Postmodern openings, 2(5), 55-88.

41. Solomon, J. (1998). Our decentered culture: The postmodern worldview. The postmodern presence: Readings on postmodernism in American culture and society, 35-50.

42. Tauber, E. M. (1972). Why do people shop. Journal of Marketing, 30, October, 46-72.

43. The Economist (2013). "The Rise of the Sharing Economy". Recuperado el 10 de noviembre del 2019 de http :// www.economist.com/news/ leaders/21573104-internet-everything-hirerisesharing-economy.

44. Thomas, M. J. (1997). Consumer market research: does it have validity? Some postmodern thoughts. Marketing Intelligence \& Planning.

45. Williams, A. (2012). Understanding the hospitality consumer. Routledge.

46. Zervas, G., Proserpio, D., \& Byers, J. (2015). A first look at online reputation on Airbnb, where every stay is above average. 